\title{
Comparative study of three types of fine recycled aggregates from construction and demolition waste (CDW), and their use in masonry mortar fabrication
}

\author{
P. Saiz Martínez a, *, M. González Cortina a , F. Fernández Martínez b \\ A. Rodríguez Sánchez ${ }^{b}$ \\ ${ }^{a}$ Architectural Construction and Control Department, Higher Technical School of Building Construction, Madrid Polytechnic University, Avenida Juan de \\ Herrera 6, 28040 Madrid, Spain \\ ${ }^{\mathrm{b}}$ Chemistry and Polymers Department, University School of Technical Industrial Engineering, Technical University of Madrid, Ronda de Valencia 3,28012 \\ Madrid, Spain
}

\begin{abstract}
A B S T R A C T
This research aims to study feasibility of incorporation of fine fraction of recycled aggregates coming from construction and demolition waste in cement-based masonry mortar fabrication. Initially, three types of recycled aggregates: concrete, mixed and ceramic recycled aggregates, were characterized in terms of physical, mechanical and chemical properties. There were used 1:3 and 1:4 cement-toaggregate proportions and replacement percentages of $50 \%, 75 \%$ and $100 \%$ respectfully for three types of studied recycled aggregates.

Physical characterization of recycled aggregates shows a continuous size distribution curve, lower density and higher absorption, what makes the usage of additive necessary to obtain appropriate consistency. Main crystalline phases shown in the X-ray diffraction analysis were: calcite, quartz and gypsum. According to the results of the dosages study, recycled mortars present poorer behaviour than mortars fabricated using natural stand, however, complying with the limits established by the standards and manufacturers. Therefore, the results of this study suggest the possibility to replace $100 \%$ of natural sand with analyzed recycled aggregates.
\end{abstract}

\section{Introduction}

Massive exploitation of natural resources in the construction and building sector has been a continuing process through the times, causing gradual environmental degradation. Under the existing regulatory framework, it is vital to incorporate recycling policies which would enable effective sustainable development of construction sector

Construction and demolition waste (CDW) is produced mainly during building rehabilitation and demolition phase. The construction industry generates in European Union around 900 million tons per year of wastes, what represents $30 \%$ of all wastes produced

\footnotetext{
* Corresponding author. 9 Coin Street 12A, 28018 Madrid, Spain. Tel.: +34 675946163.

E-mail addresses: pablo.saiz@upm.es (P. Saiz Martínez), mariano.gonzalezc(i) upm.es (M. González Cortina), francisco.fernandezm@upm.es (F. Fernández Martínez), antonio.rodriguezs@upm.es (A. Rodríguez Sánchez).
}

(Eurostat, 2010). There can be obtained three types of recycled aggregates (RA) classifying them according to the compounds they are formed of: concrete RA, mixed RA and ceramic RA (Gear Project, 2012).

The average recycling rate in Europe is $50 \%$, and there are even some countries such as Denmark, Estonia and the Netherlands that recycle more than $90 \%$ of their CDW (Villoria et al., 2011). However, in Spain these rates are much lower and do not reach the objective established by the Integrated Waste Management Plan (2008).

Recycling rate is Spain is about $15 \%$ of the total production of CDW, which is used mainly as filler in road construction that is also typical for other countries (Vegas et al., 2008). The Code on Structural Concrete (EHE-08:2008) permits the usage of coarse fraction of RA in mortar fabrication, recommending substitution of up to $20 \%$ of natural sand by RA. However, the fine RA has not been considered by most standards until now because of its poorer properties. Lots of studies showed that the properties of concrete decrease as the replacement percentage of fine RA increased 
(Khatig, 2005; Shi-Cong and Chi-Sun, 2009). Therefore, the incorporation of this material in masonry mortar production implies a new alternative for recycling of CDW in the building and construction sector.

\subsection{Literature review}

Various scientific researches have studied the feasibility of incorporating fine fraction of RA in masonry mortars production. The bibliography consulted shows varying permitted replacement percentages, partly due to the heterogeneity of RA. Vegas et al. (2009) concluded that mortars can contain up to $25 \%$ of fine RA without their mechanical properties, workability and shrinkage being affected, requiring no additives.

Jiménez et al. (2013) concluded that the incorporation of up to $40 \%$ of ceramic waste in mortars production does not affect significantly the properties of cement mortar in fresh and hardened state, with exception of its density and workability.

Corinaldesi and Moriconi (2009) evaluated mechanical and rheological behaviour of cement mortars manufactured using three types of RA: rejected prefabricated concrete material, recycled bricks waste and plant recycling rubble. In three cases, $100 \%$ of RA has been used, determining poorer mechanical behaviour and higher mortar-brick bond strength of recycled mortars comparing to traditional mortars.

Corinaldesi (2012) replaced quartz sand in the production of cement and hydraulic lime mortars using ceramic aggregates coming from crushed red brick. The aggregates were incorporated in saturated-dried condition without admixtures use. It was concluded that fine crushed brick aggregates present poorer mechanical properties than coarse crushed brick aggregates due to the greater angularity of the coarse fraction. However, fine crushed brick aggregates present the best mortar-brick bond strength.

Martinez et al. (2013) compared the properties of mortars made using three types of natural sand and three types of recycled aggregates from concrete, ceramic and masonry waste. 1:6 cementaggregate proportion and $100 \%$ substitution of natural sand by recycled aggregates rate were used. It was concluded that mortars fabricated with recycled aggregates present poorer mechanical strength properties, except natural sand from Cuba, because of low quality of this sand. Higher water absorption and shrinkage were obtained in recycled mortars.

Fernández et al. (2015) evaluated the possibility to incorporate fine fractiōñ ôf RA in̄ minasonry mortars using CEM II/BL $32.5 \mathrm{~N}$. Obtained results show that replacement ratio of $50 \%$ can be achieved in mortar for indoor use.

The main aim of this work is the evaluation of recycled mortars properties both in fresh and hardened state using different replacement percentages of natural sand with three types of RA coming from collaborating recycling plant. This study results present a contribution regarding the published works, and could help to increase CDW recycling rates, reducing in such a way consumption of natural recourses in the construction sector.

\section{Materials and methods}

\subsection{Materials}

The following materials were used in this research: cement, sand, additive and water.

\subsubsection{Cement}

The binders used in the study were CEM II/B - L $32.5 \mathrm{~N}$ and CEM IV/B (V) $32.5 \mathrm{~N}$, suitable for mortar fabrication and masonry in general. Spanish and European standard UNE-EN 197-1:2011 and the Instruction for the cement placing (RC-08) specify the properties of these cements. Their main characteristics and chemical composition are shown in Table 1.

\subsubsection{Aggregates}

Aggregates employed to prepare reference mortars were provided by the Cemex Company. Recycled sand was provided by an integrated CDW Treatment Plants of Madrid Region. Three samples of RA were employed: fine recycled aggregates RA-1, RA-2 and RA-3 originated from ceramic recycling process, mixed recycling process and concrete recycling process respectively. RA passed through the pre-screening, trommel separation of fines, crushing and grinding, and final screening obtaining fine $\mathrm{RA}$ of $0 / 6 \mathrm{~mm}$ size. The fine fraction was sieved in the laboratory to remove particles lager than $4 \mathrm{~mm}$ and shorter than $0.063 \mathrm{~mm}$.

\subsubsection{Additive}

Recycled mortars were prepared using the superplasticizer additive Glenium Sky 604 by BASF Company. This is a high-activity water reducing/superplasticising additive based on polycarboxylates. Glenium SKY 604 was prescribed by BASF Company technical department to improve consistency of recycled mortars.

\subsection{Characterization}

Characterization of fine RA samples was based on the technical requirements regulated by the standard UNE-EN-13139:2002: "Aggregates for mortar". Three types of fine RA comply with the upper and lower size limits and the maximum percentage of fines established by the standard for masonry mortars. The results of physical and chemical characterization of RA and natural aggregates (NA) are presented in Table 2 .

Fig. 1 shows graphical representation of RA used in this study according to the requirements established by the UNE-EN-9332:1995 and the UNE-EN-933-1:2012 standards, in particular Part 1: Determination of particle size distribution "Sieving method".

As pointed by other authors, size distribution is one of the most important properties of aggregates (Etxeberria et al., 2007; Tam et al., 2008). Analyzed RA present continuous size distribution curve (Fig. 1) situated within the limits established by the referencence standard.

To complete the characterization of RA the following tests were carried out: X-ray diffraction analysis and X-ray fluorescence method. Obtained results are presented in Tables 3 and 4.

Crystal structures and purity of samples were tested by X-ray diffraction (XRD) analysis, where the X-ray diffraction pattern was

Table 1

Characteristics of CEMI//B-L $32.5 \mathrm{~N}$ and CEMIV/B(V) $32.5 \mathrm{~N}$.

\begin{tabular}{|c|c|c|}
\hline & $\mathrm{CEM} \mathrm{Il} / \mathrm{B}-\mathrm{L} 32.5 \mathrm{~N}$ & CEM IV/B (V) $32.5 \mathrm{~N}$ \\
\hline \multicolumn{3}{|l|}{ Physical characteristics } \\
\hline Density $\left(\mathrm{g} / \mathrm{cm}^{3}\right)$ & 3.05 & 2.85 \\
\hline Blaine specif. area $\left(\mathrm{cm}^{2} / \mathrm{g}\right)$ & 4000 & 4400 \\
\hline Initial set (min) & 175 & 230 \\
\hline Final set $(\mathrm{min})$ & 275 & 285 \\
\hline \multicolumn{3}{|l|}{ Chemical characteristics } \\
\hline $\mathrm{Al}_{2} \mathrm{O} 3$ & 3.25 & 13.40 \\
\hline $\mathrm{CaO}$ & 60.10 & 35.55 \\
\hline $\mathrm{Fe}_{2} \mathrm{O} 3$ & 2.56 & 3.50 \\
\hline $\mathrm{K}_{2} \mathrm{O}$ & 0.26 & 1.80 \\
\hline Mgo & 1.75 & 2.60 \\
\hline $\mathrm{SiO}_{2}$ & 18.13 & 31.90 \\
\hline $\mathrm{TiO}_{2}$ & 0.14 & 0.60 \\
\hline $\mathrm{MnO}$ & 0.02 & 0.05 \\
\hline $\mathrm{P}_{2} \mathrm{O} 5$ & 0.16 & 0.33 \\
\hline $\mathrm{NaO}_{2}$ & 0.22 & 0.02 \\
\hline Loss on ignition & 11.85 & 8.60 \\
\hline
\end{tabular}


Table 2

Aggregates characteristics.

\begin{tabular}{|c|c|c|c|c|c|}
\hline \multicolumn{6}{|c|}{ Aggregates characteristics } \\
\hline Test & Standard & RA 1 & RA 2 & RA 3 & NA \\
\hline Fine content (\%) & UNE-EN-933-1 & 4.53 & 4.13 & 3.91 & 2.61 \\
\hline Particle form & UNE-EN-13139 & No relevant & No relevant & No relevant & - \\
\hline Fineness modulus (\%) & UNE-EN-13139 & 4.77 & 5.27 & 4.26 & 4.32 \\
\hline Friability (\%) & UNE-EN83115 & 26.23 & 27.20 & 24.02 & 22.61 \\
\hline Bulk dens. $\left(\mathrm{kg} / \mathrm{m}^{3}\right)$ & UNE-EN-1097-3 & 1272 & 1253 & 1330 & 1560 \\
\hline Dry dens. $\left(\mathrm{kg} / \mathrm{m}^{3}\right)$ & UNE-EN-1097-6 & 2130 & 2130 & 2100 & 2450 \\
\hline Water absorption (\%) & UNE-EN-1097-6 & 7.48 & 6.88 & 6.12 & 0.92 \\
\hline
\end{tabular}

measured using the $\mathrm{Cu}-\mathrm{K} \alpha$ radiation $(\lambda=1.540598 \AA)$ with a Siemens D500 diffractometer equipped with a graphite monochromator. Data were collected at $300 \mathrm{~K}$ over an angular range of $10^{\circ} \leq 2 \theta \leq 110^{\circ}$ by scanning in steps of $0.05^{\circ}$ and counting times of 10 s. $40 \mathrm{kV}$ voltage and $20 \mathrm{~mA}$ current were used.

\subsection{Mortar mix proportions}

Based on the results of characterization of different materials analyzed in this study, tests of dosages and different properties of RA were conducted.

The testing programme was developed using two types of binders: CEM II/B-L $32.5 \mathrm{~N}$ and CEM IV/B (V) 32.5. There were suggested three substitution percentages to replace natural sand with three types of RA: $50 \%, 75 \%$ and $100 \%$, and cement-toaggregate by dry weight proportions were $1: 3$ and 1:4. RA coming from treatment plants was sieved in the laboratory, eliminating material retained on the $4 \mathrm{~mm}$ sieve and material passed through $0.063 \mathrm{~mm}$ sieve, because of poorer characteristics of aggregates of this fraction.

Preparation of all mixes was performed using the same technique and equipment. The mixes containing $50 \%$ and $75 \%$ of RA were completed with natural sand to reach $100 \%$ of necessary aggregate. All the mixes were prepared using $1 \%$ of additive over the weight of cement, complying with the limits established by the manufacturer. According to the technical data, this additive can reduce the water content of the mortar while maintaining workability and improving its strength, durability and shrinkage.

Table 5 summarizes different dosages employed in the study. The water content of each mortar was set experimentally to achieve a consistency of $175 \pm 10 \mathrm{~mm}$ complying with UNE-EN 1015-2:1998
Table 3

Recycled aggregates mineralogy.

\begin{tabular}{llll}
\hline Mineral phase & \multicolumn{2}{l}{ Mineral relative abundance } \\
\cline { 2 - 4 } & RA 1 & RA 2 & RA 3 \\
\hline Calcite & $* * * *$ & $* * * *$ & $* * * *$ \\
Gypsum & $* *$ & $* *$ & - \\
Phlogopite & $* *$ & $* *$ & $*$ \\
Quartz & $* * * * * * * *$ \\
Sanidine & $* * *$ & $* * * *$ & $* *$ \\
\hline
\end{tabular}

standard requirements for plastic mortar. For that reason, due to high water absorption of RA it was necessary to increase water use as the percentage of RA incorporation grows.

\subsection{Test methodology}

Testing programme was divided into two parts. During the first one tests of consistency, wet density, flexural and compressive strength, bond strength and shrinkage were carried out.

The wet density of mortars was measured according to the technical prescriptions established by the UNE-EN1015-6:1998 standard. The bond strength test was carried out on a ceramic support of $400 \times 500 \times 50 \mathrm{~mm}$, with a specimen diameter of $50 \mathrm{~mm}$ and coating thicknesses of $10 \mathrm{~mm}$, following the technical prescriptions of the UNE-EN 1015-12:2000 standard. Compressive and flexural strength were analyzed using prismatic specimens of $40 \times 40 \times 160 \mathrm{~mm}$, being cast and cured in a humid chamber at $20{ }^{\circ} \mathrm{C}$ during 28 days. Flexural and compressive strength were determined following the technical prescription of the UNE-EN 1015-11:1999 standard. Shrinkage test was carried out using a

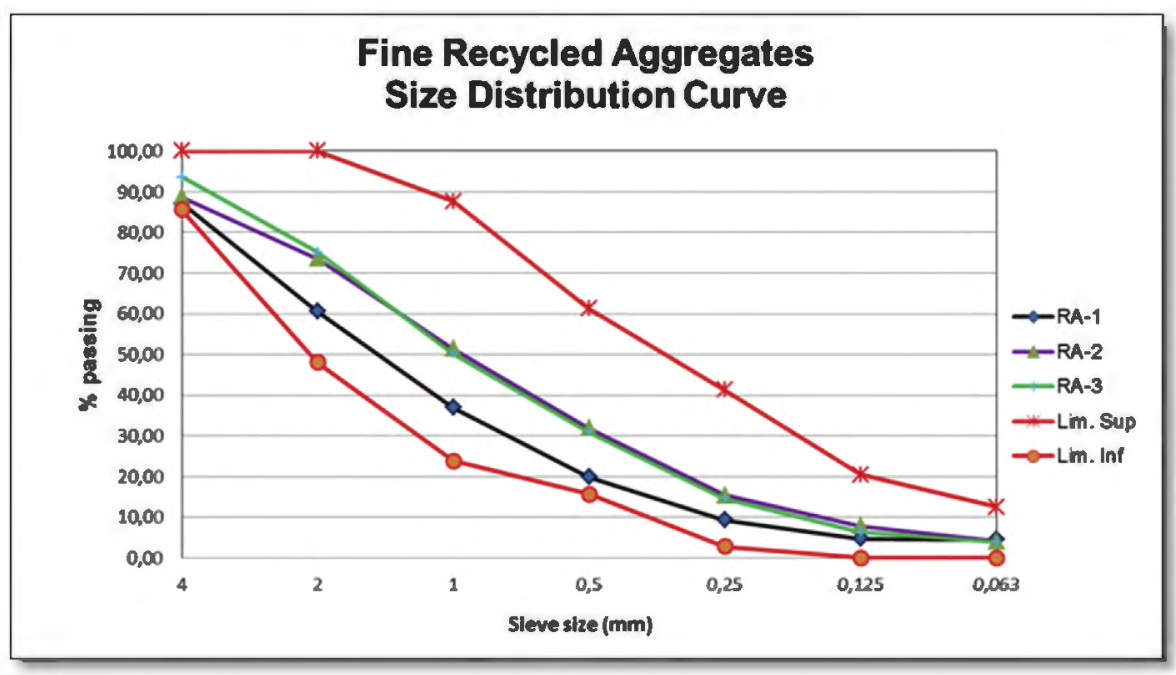

Fig. 1. Recycled aggregate size distribution curve compared to the limits of NBE.FL 90 adapted to sieve size established by UNE-EN-933-2:1995. 
Table 4

$\mathrm{X}$ Ray fluorescence test results.

\begin{tabular}{|c|c|c|c|c|c|c|c|c|c|c|c|c|}
\hline Samples & $\mathrm{Al}_{2} \mathrm{O}_{3}$ & $\mathrm{CaO}$ & $\mathrm{Fe}_{2} \mathrm{O}_{3}$ & $\mathrm{~K}_{2} \mathrm{O}$ & $\mathrm{MgO}$ & $\mathrm{SiO}_{2}$ & $\mathrm{MnO}$ & $\mathrm{TiO}_{2}$ & $\mathrm{SO}_{3}$ & $\mathrm{P}_{2} \mathrm{O}_{5}$ & $\mathrm{Na}_{2} \mathrm{O}$ & 1.Loss $\%$ \\
\hline RA 1 & 10.10 & 15.70 & 2.44 & 2.31 & 1.81 & 45.50 & - & 0.32 & 3.12 & 0.12 & 0.95 & 16.50 \\
\hline RA 2 & 6.57 & 11.58 & 1.57 & 2.17 & 0.61 & 63.50 & 0.024 & 0.17 & 2.44 & 0.08 & 0.35 & 9.50 \\
\hline RA 3 & 6.48 & 10.67 & 1.22 & 2.16 & 0.54 & 67.70 & 0.022 & 0.15 & 1.43 & 0.10 & 0.22 & 8.60 \\
\hline
\end{tabular}

shrinkage tray with a digital comparator at one of its ends. The aim of this test is to measure mortar length variations during the initial phase of hydration (plastic and hydraulic shrinkage). The test was carried out in the laboratory during $72 \mathrm{~h}$ with a temperature of $20{ }^{\circ} \mathrm{C} \pm 1{ }^{\circ} \mathrm{C}$ and humidity of $60 \% \pm 2 \%$, taking readings every $60 \mathrm{~min}$.

Moreover, statistical analysis of the data was provided presenting ANOVA tables. Design of experiments carried out in this part of study is based on the following factors and levels (Table 6):

Once the cement that shows better results was determined, in the second part of the study the following properties of RA were analyzed: workability period, dry bulk and real density, water absorption by capillarity, crystallization of salts and frost resistance.

Workability period of fresh mortar is measured as a period of time in minutes that it takes for mortar to reach strength of $0.5 \mathrm{~N} /$ $\mathrm{mm}^{2}$, using a penetrometer (UNE-EN 1015-9:1999). Dry bulk density of hardened mortar was determined following technical prescription of the UNE-EN 1015-10:1999 standard. Water absorption by capillarity test was carried out according to the technical prescriptions of the UNE-EN 1015-18:2002 standard. For that reason, the samples of $40 \times 40 \times 80 \mathrm{~mm}$ were partially immersed in water by one of the surfaces, waterproofing their lateral surfaces. Crystallization of salts test was realized following the UNE-EN 12370:1999 standard on natural stone specifies, because of behaviour analogies with mortars. Samples were dried in a stove and introduced into a sodium sulphate solution decahydrated by $14 \%$ during $2 \mathrm{~h}$, to be dried later in an oven during $16 \mathrm{~h}$. As for the frost resistance, as in case of crystallization of salts, there is no specific regulation on mortars, so the test was adapted to the UNEEN 12371:2001 standard requirements on natural stone subjected to freeze-thaw cycles. Mortar samples underwent 25 cycles, being previously dried in an oven until constant mass was reached: one freeze phase under $-15^{\circ} \mathrm{C}$ and one thaw phase maintaining samples during $18 \mathrm{~h}$ in immersion under $10^{\circ} \mathrm{C} \pm 2{ }^{\circ} \mathrm{C}$.

The following code was employed for the mixes identification:

$R A-N^{\circ}-X$

where $\mathrm{RA}=$ Recycled aggregates.

$\mathrm{N}^{\circ}=$ Recycled aggregate type $(1=$ ceramic recycled aggregate, $2=$ mixed recycled aggregate and $3=$ concrete recycled aggregate)

$\mathrm{X} \%=$ Type of cement $(\mathrm{II}=\mathrm{CEM} \mathrm{II} / \mathrm{B}-\mathrm{L} 32.5 \mathrm{~N}$ and $\mathrm{IV}=\mathrm{CEM} \mathrm{IV} / \mathrm{B}$ (V) $32.5 \mathrm{~N}$ ).

Table 5

Dosages.

\begin{tabular}{lrlll}
\hline Dosage & \multicolumn{5}{l}{} \\
\hline c/a & RA $\%$ & Cement & Aggregate & Water \\
\hline $1: 3$ & $50 \%$ & 1 & 3 & 0.57 \\
& $75 \%$ & 1 & 3 & 0.64 \\
& $100 \%$ & 1 & 3 & 0.68 \\
$1: 4$ & $50 \%$ & 1 & 4 & 0.75 \\
& $75 \%$ & 1 & 4 & 0.86 \\
& $100 \%$ & 1 & 4 & 0.89 \\
\hline
\end{tabular}

Note: $1 \%$ of additive over the weight of cement.

Note: same water amount for all RA and cement.

\section{Experimental results and discussion}

\subsection{Recycled aggregates characterization}

Particle size of RA is a result of grinding and sieving process type employed by a treatment plant. As it is shown in Fig. 1, three types of analyzed RA present continuous particle size distribution curve. This characteristic has a direct influence on such properties of mortars as mechanical strength, workability, compaction and durability (Etxeberria et al., 2007; Tam et al., 2008).

As it can be observed in Table 2, obtained density of RA is lower than that of natural sand, while water absorption values of RA are significantly higher. This characteristic which is general for RA is caused mainly by the amount of attached mortar (Etxeberria et al., 2007; Lamond et al., 2002). The obtained results are similar to those presented in other researches (Jiménez et al., 2013; Vegas et al., 2009) and produce higher cement and water demand of recycled mortars. There are no standards regulating this property of mortars, however, the EHE-08:2008 standard limits water absorption values to $7 \%$ for structural concrete. Nevertheless, other studies consider values up to $10 \%$ to be viable for the usage of RA in construction sector (Gear Project, 2012).

Main crystalline phases obtained in the X-ray diffraction analysis (Table 3) are quartz and calcite. Observed phases, with the exception of quartz, do not show a high crystalline state presenting low intensities. Other observed phases are: sanidine, phlogopite and gypsum.

The results obtained in the X-ray fluorescence analysis (Table 4) show high silicate content for three types of RA. These silicates are mainly calcium and aluminium silicates. RA contain higher percentage of these two elements: $10.10 \%\left(\mathrm{Al}_{2} \mathrm{O}_{3}\right)$ and $15.70 \%(\mathrm{CaO})$, values which are within the ranges found by Angulo et al. (2009). The most unfavourable value of $\mathrm{SO}_{3}$ of $3.12 \%$ is presented by ceramic RA, what is equal to the amount of Sulphur (S) of 1.248. This value is higher than the limit of $1 \%$ established by the UNE-EN 13139:2002 standard "Aggregates for mortar". High content of this element may provoke gradual loss of mechanical strength and consequently poorer durability in recycled mortar.

\subsection{Recycled mortar characterization}

\subsubsection{Part 1}

Recycled mortars were characterized through the following tests: wet density, flexural and compressive strength, bond strength and shrinkage. Obtained results are shown in Figs. 2-4, 6 and 7.

A one-way analysis of variance was carried out to determine whether the mortar type factor had a statistically significant effect on the studied properties. A multiple range test was also conducted to determine which means were significantly different from the

Table 6

Experimental design code.

\begin{tabular}{ll}
\hline Factors & Levels \\
\hline Substitution \% (A) & $100 \%(\mathbf{1}), 75 \%(\mathbf{2})$ and $100 \%(\mathbf{3})$ \\
Cement type (B) & Cem II (a) and Cem IV (b) \\
RA type (C) & Ceramic (cer), concrete (c), and mixed (m) \\
Dosage (D) & $1: 3(\mathbf{x})$ and $1: 4(\mathbf{y})$ \\
\hline
\end{tabular}




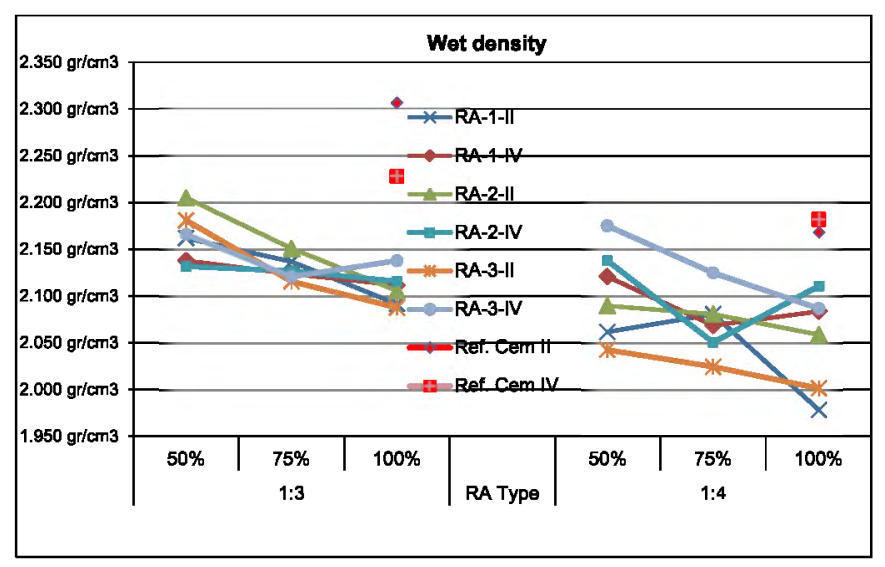

Fig. 2. Wet density results.

others. The results include a table as an example of the mean for a level. Homogeneous groups that do not overlap indicate a significant difference between the means, while homogeneous groups that overlap indicate no significant difference between the means.

It can be observed in Fig. 2 that wet density values with substitution rate of $100 \%$ are slightly lower than values of reference mortars fabricated using natural sand. It can be also observed that generally wet density values become lower for three types of RA as the substitution percentage of natural sand with RA increases. Values obtained in this study are similar to those find by other authors (Silva et al., 2010; Vegas et al., 2009). A one-way ANOVA was carried out to determinate whether the mortar type factor had a statistically significant effect on wet density. The P-value $(<0.05)$ of the F-test shows that cement type factor, substitution percentage and dosage are statistically significant as the $A B, B C$ and $B D$ interactions at a $95 \%$ confidence level.

A multiple range test was conducted to identify the significant differences between the means. An example is shown in Table 7. As for substitution percentage, three homogeneous groups with significant differences in the mean values of the wet density of fresh mortar were presented in columns of Xs. Using the same method, different homogeneous groups were obtained for cement types and dosage factors, concluding that the mean values are different for both factors. However, differences in the mean values were obtained in case of RA type factor.

The same applies to bond strength test (Fig. 3) while analyzing results for both types of cement. The mixes with $100 \%$ substitution

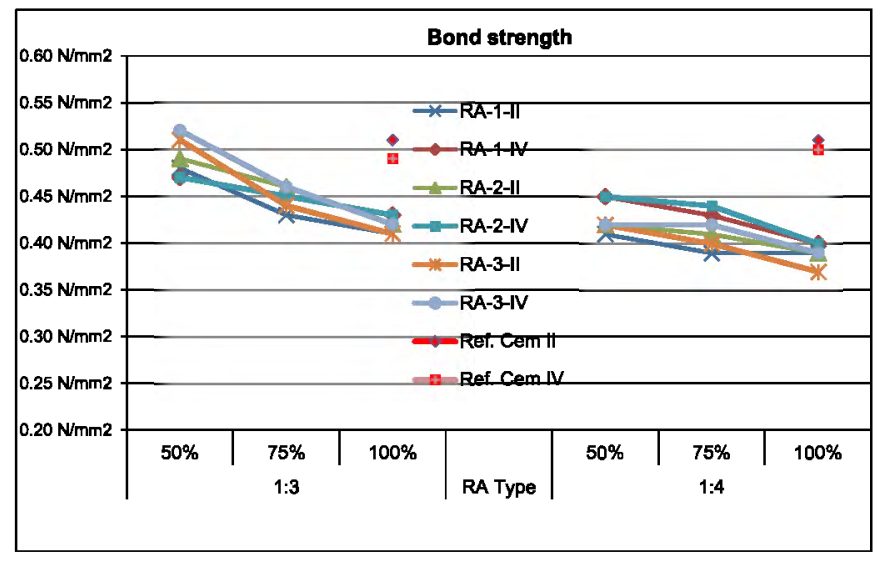

Fig. 3. Bond strength results.

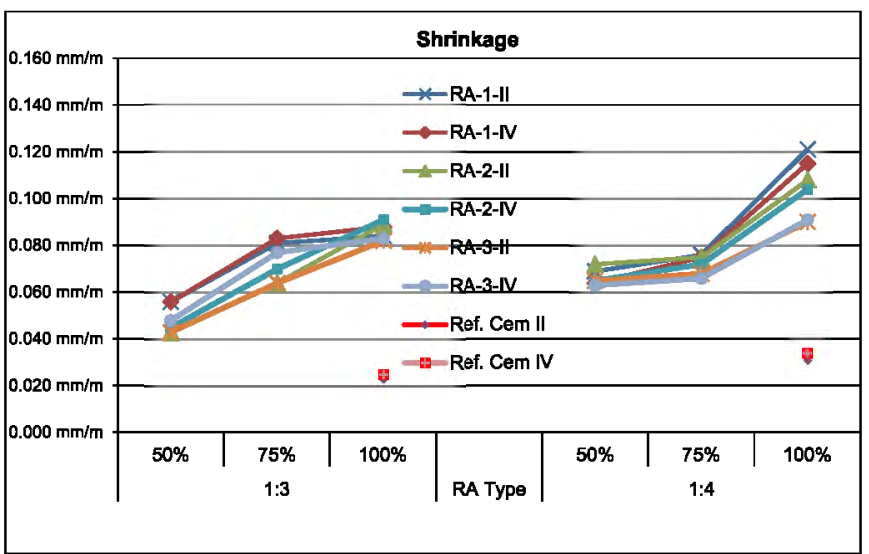

Fig. 4. Shrinkage results

rate present similar results in three cases, complying with the limit of $0.30 \mathrm{~N} / \mathrm{mm}^{2}$ established by the UNE-EN 998-1:2010 standard. Other researches present similar bond strength values: $0.37 \mathrm{~N} / \mathrm{mm}^{2}$ (Jiménez et al., 2013) or $0.40 \mathrm{~N} / \mathrm{mm}^{2}$ (Silva et al., 2010) with substitution rate of $50 \%$ and $1: 4$ cement-to-aggregate proportion.

In case of bond strength, the P-value $(<0.05)$ of the F-test shows that cement type, substitution percentage, dosage factors and $A D$, $B C$ and $C D$ interactions have statistically significant effect on this property at a $95 \%$ confidence level.

As it is presented in Table 8 , conducting a multiple range test, the significant differences between the mean values were presented. RA type was the unique factor which did not present significant differences in the mean values.

No reference standards which establish the procedure of shrinkage test was followed, so an experimental procedure was used in the study (Fig. 5). Mortars were studied at laboratory temperature $\left(20^{\circ} \mathrm{C} \pm 2{ }^{\circ} \mathrm{C}\right)$ during $72 \mathrm{~h}$, taking readings every 60 min to determine hydraulic shrinkage.

The results of shrinkage test (Fig. 4) show higher values compared to reference mortars. The mixture that gives the highest shrinkage value of $0.121 \mathrm{~mm} / \mathrm{m}$ is one that corresponds to ceramic aggregate with $1: 4$ proportion. These values are significantly higher than that of mortars fabricated with natural sand, what may cause cracking and fissuring in recycled mortar. Similar results were obtained in other researches (Mesbah and Buyle-Bodin, 1999).

The P-value $(<0.05)$ of the F-test indicates that RA type, substitution percentage, dosage factors and $A D$ interactions present statistically significant effect on the shrinkage at a $95 \%$ confidence level. A multiple range test was conducted to identify the significant differences between the means, as it is presented in Table 9. The factor which did not show significant differences between the

Table 7

Multiple range test for the wet density by \% substitution. Method: 95.0\% LSD.

\begin{tabular}{lllll}
\hline \%Substitution & Count & LS mean & LS sigma & Homogeneous groups \\
\hline 1 & 12 & 1.44254 & 0.00223979 & $\mathrm{X}$ \\
2 & 12 & 1.44931 & 0.00223979 & $\mathrm{X}$ \\
3 & 12 & 1.46088 & 0.00223979 & $\mathrm{X}$ \\
\hline
\end{tabular}

Table 8

Multiple range test for the bond strength by dosage. Method: $95.0 \%$ LSD.

\begin{tabular}{lllll}
\hline Dosage & Count & LS mean & LS sigma & Homogeneous groups \\
\hline $\mathrm{y}$ & 18 & 0.407778 & 0.0021606 & $\mathrm{X}$ \\
$\mathrm{x}$ & 18 & 0.452778 & 0.0021606 & $\mathrm{X}$ \\
\hline
\end{tabular}




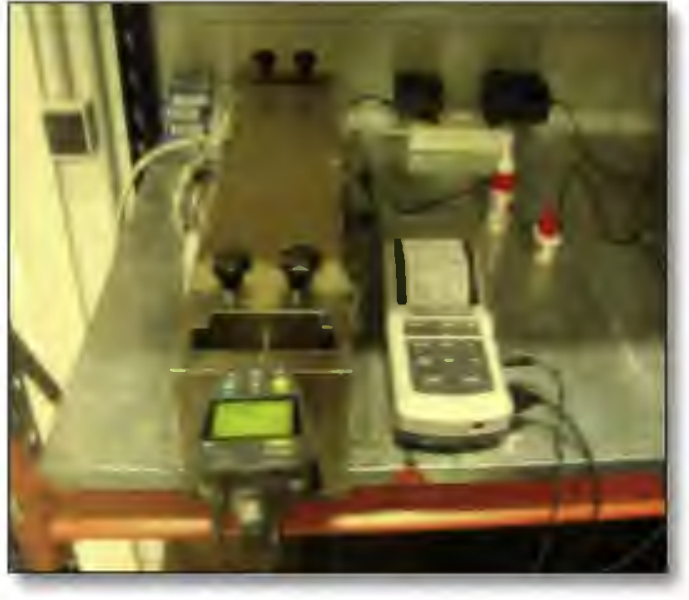

Fig. 5. Shrinkage test.

means was cement type factor. Regarding RA type, two homogeneous groups with significant differences in the mean values of the shrinkage were obtained and presented in columns of Xs, observing higher shrinkage of ceramic RA than that of concrete RA and mixed RA.

In relation to mechanical strength, flexural strength (Fig. 6) decreases as percentage of RA becomes higher. The mix that presents the lowest flexural strength value is one that was fabricated using CEM II/B-L $32.5 \mathrm{~N}$ with 1:4 proportion. Flexural strength of this mix is $2.94 \mathrm{MPa}$, which means a loss of strength of $25 \%$ with respect to the reference mix.

The P-value $(<0.05)$ of the F-test indicates that all the factors including BD interaction have statistically significant effect on the flexural strength at $95 \%$ confidence level. A multiple range test was carried out to identify the significant differences between the mean values. There are no differences between the mean values of flexural strength of mixes prepared with ceramic RA and mixed RA, which leads to the conclusion that mortars fabricated using concrete RA present higher flexural strength.

There were presented significant differences between the levels of dosage and cement type factors. The highest flexural strength values were obtained in the mixes elaborated with CEM IV using 1:3 dosage. No significant differences were determined between $75 \%$ and $100 \%$ substitution rates. However, comparing to $50 \%$ substitution rate significant differences were obtained.

Obtained values of compressive strength (Fig. 7) also indicate poorer properties of recycled mortars compared to mortars fabricated using natural sand. The mix that presents the lowest compressive strength value of $9.07 \mathrm{MPa}$ corresponds to ceramic RA fabricated with CEM II/B-L $32.5 \mathrm{~N}$ with $1: 4$ proportion, what is similar to the results of flexural strength test. Nevertheless, the values that were obtained comply with existing standards that establish $7.5 \mathrm{MPa}$ as a minimum acceptable value for compressive strength, what makes it unnecessary to modify the dosage.

A one-way ANOVA was carried out to determinate whether the mortar type factor had a statistically significant effect on compressive strength. The P-value $(<0.05)$ of the F-test shows that

Table 9

Multiple range test for the shrinkage by RA type. Method: 95.0\% LSD.

\begin{tabular}{lllll}
\hline Dosage & Count & LS mean & LS sigma & Homogeneous groups \\
\hline $\mathrm{c}$ & 12 & 0.0711667 & 0.00149971 & $\mathrm{X}$ \\
$\mathrm{m}$ & 12 & 0.0748333 & 0.00149971 & $\mathrm{X}$ \\
$\mathrm{cer}$ & 12 & 0.0806667 & 0.00149971 & $\mathrm{X}$ \\
\hline
\end{tabular}

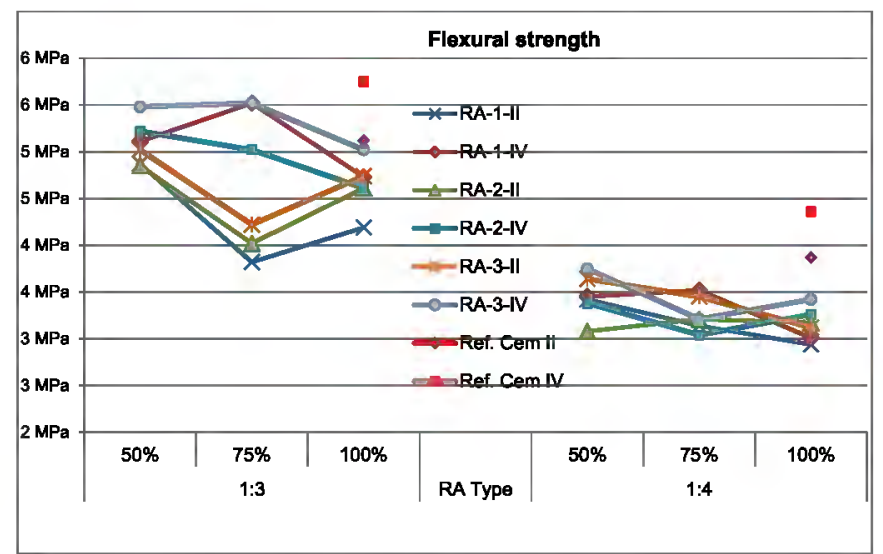

Fig. 6. Flexural strength results

all the factors and $A B$ interaction are statistically significant at a $95 \%$ confidence level. Cement type and dosage presented significant differences in their levels. CEM IV and 1:3 dosage obtained higher compressive strength values.

Between $75 \%$ and $100 \%$ substitution rates there were no significant differences in the mean values, however, comparing both substitution rates to $50 \%$ rate significant differences were obtained. Mixes fabricated with concrete RA are significantly different from mixes elaborated with ceramic RA and mixed RA, obtaining higher levels of compressive strength (Table 10).

According to the obtained results, it is concluded that generally recycled mortars fabricated using CEM IV/B (V) $32.5 \mathrm{~N}$ present better results in performed tests, because of pozzolanic activity of fly ash present in this type of cement. Mixes prepared with $100 \%$ of RA comply with existing standards regulating mortars for carried out tests, thus parts 2 and 3 of testing programme were realized using mixes with this substitution ratio.

\subsubsection{Part 2}

Fig. 8 shows the results obtained in the workability period test, dry bulk and real density test and water absorption by capillarity analysis for each mix elaborated with CEM IV/B (V) $32.5 \mathrm{~N}$ and replacement ratio of $100 \%$.

It can be observed in Fig. 8 that recycled mortars workability period is shorter, what means that recycled mortars maintain properties in fresh state less time without necessity to add water comparing to the reference mortars. Obtained results are similar to those presented by Jiménez et al. (2013) with replacement ratio of

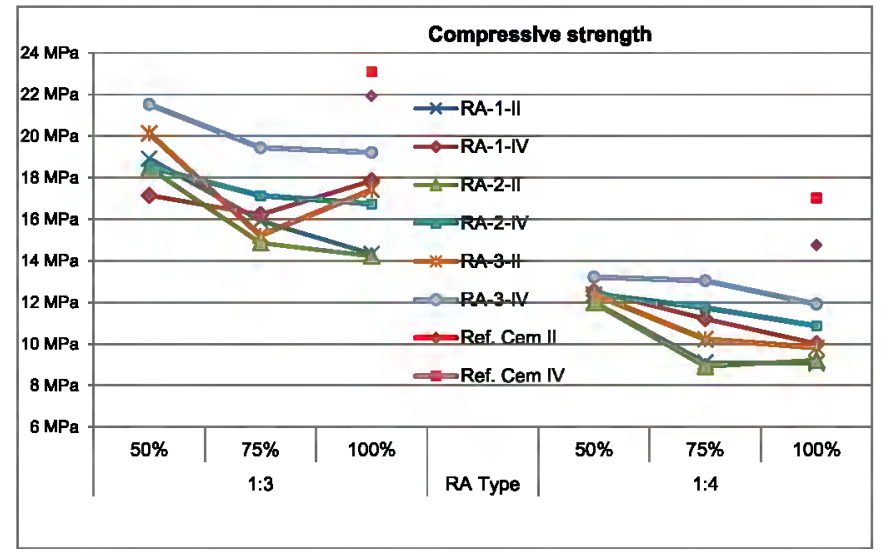

Fig. 7. Compressive strength results. 
Table 10

Multiple range test for the compressive strength by RA type. Method: 95.0\% LSD.

\begin{tabular}{lllll}
\hline Dosage & Count & LS mean & LS sigma & Homogeneous groups \\
\hline $\mathrm{c}$ & 12 & 15.2958 & 0.214503 & $\mathrm{X}$ \\
$\mathrm{m}$ & 12 & 13.7558 & 0.214503 & $\mathrm{X}$ \\
$\mathrm{cer}$ & 12 & 13.6958 & 0.214503 & $\mathrm{X}$ \\
\hline
\end{tabular}

40\% using ceramic RA and Vegas et al. (2009) with replacement ratio of $25 \%$ using RA from concrete rubble.

The highest values of dry density were presented by natural sand. Values observed in recycled mortars were quite similar, and observed density values are caused by low density of RA (Bravo et al., 2015). Obtained results are similar to the findings of other studies (Jiménez et al., 2013; Vegas et al., 2009).

Real density of hardened mortar was analyzed with a stereopycnometer, used for measuring volume of solid objects. Obtained values of recycled mortars are poorer compared to reference mortar values. Observed differences between real density and dry bulk density are directly linked to the total porosity. Thus, samples with the highest real density and the lowest dry bulk density, as in case of mixes elaborated with 1:4 dosage, present the highest volume of porosity and the highest communication between pores.

The results show higher water absorption by capillarity of recycled mortars due to the high absorption of RA. Similar tendencies were observed by other authors in their studies, presenting similar absorption by capillarity values, however with lower percentage of RA incorporation (Jiménez et al., 2013; Silva et al., 2009; Vegas et al., 2009).

in terms of crystallization of salts, visual inspection of the samples during the test shows material surface losses during the cycles (Fig. 9). The samples that present the poorer mechanical behaviuuir presented higher mass losses, to the extent that some samples (mixes elaborated with $100 \%$ of mixed and ceramic RA) made with CEM II/B - L $32.5 \mathrm{~N}$ have been fell apart before completing 15 planned cycles.

As for frost resistance, visual appearance of samples indicates that no important damage was produced in samples fabricated with $100 \%$ of RA, and observed strength loss was not significant for analyzed recycled mortars.

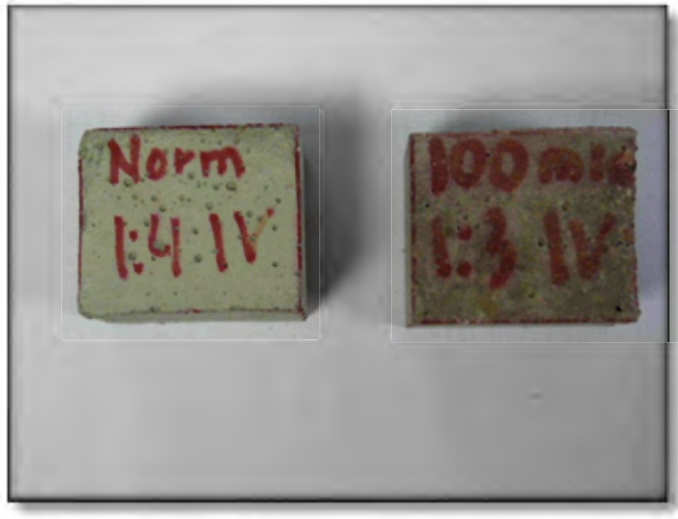

Fig. 9. Crystallization of salts

\section{Conclusions}

This study analyses the possibility to replace $100 \%$ of natural sand with fine fraction of RA in masonry mortars, comparing the properties of recycled mortars fabricated using three types of RA marketed in Spain. The main conclusions that arise from this study are given below:

- Three types of RA analyzed in this study present continuous size distribution curve, poorer density and higher water absorption compared to natural sand. Obtained absorption values are between $5 \%$ and $10 \%$ what are acceptable for recycled mortars.

- Ceramic RA presents value of Sulphur (S) which is higher than the limit established by the standards, thus $S$ content is identified as one of determining factors for the viability of RA incorporation in masonry mortars fabrication.

- Main crystalline phases were calcite and quartz, observed in three types of analyzed RA. The results of the X-ray fluorescence method show that RA are mainly composed of silicates, being most of them calcium and aluminium silicates.

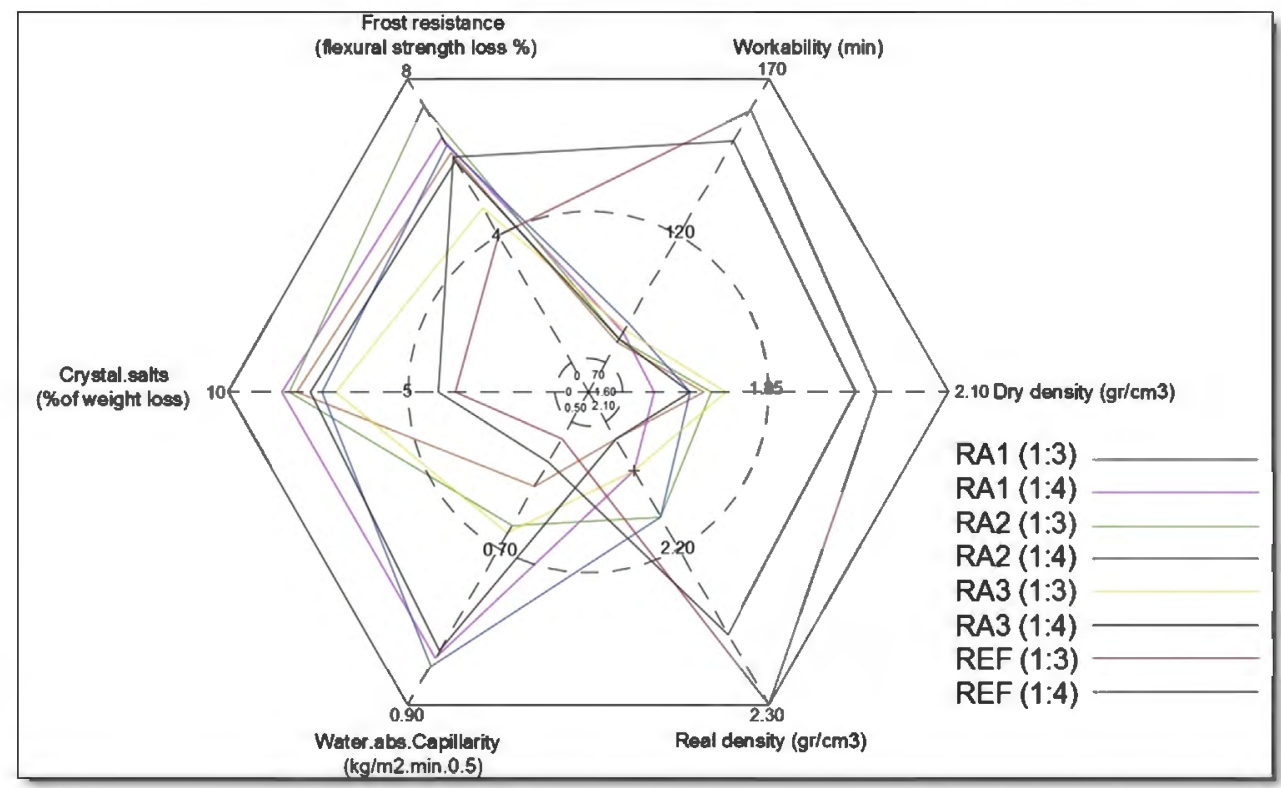

Fig. 8. Characterization of recycled mortar. 
- Wet bulk density, dry bulk density and real density decrease lineally as replacement ratio of natural sand by RA increases, due to lower density of RA.

- Due to high absorption of RA, important reduction of workability period is observed in recycled mortars. Because of this characteristic absorption by capillarity increase is also observed.

- Mechanical strength of recycled mortars fabricated with $100 \%$ of RA is poorer compared to mixes made with natural sand. According to the statistical analysis, better results were obtained in the mixes made with CEM IV/B (V) $32.5 \mathrm{~N}$ and concrete RA.

- Both compressive and bond strength values of recycled mortar comply with established standards, allowing its use in construction using studied RA in suggested proportions.

- Recycled mortars shrinkage values are superior to those of the reference mortars. Statistical analysis determined better behaviour of concrete RA in terms of shrinkage, presenting no significant differences between ceramic and mixed RA.

- Recycled mortars show poorer behaviour in terms of crystallization of salts and frost resistance, what is similar to the results of other researches.

- Recycled mortar placing is similar to the reference mortar, taking into consideration the humidity content of the aggregate and workability decrease of mortar elaborated with RA.

- Mixes elaborated with RA3 present better properties then those fabricated with RA1 and RA2. However, there have been found no significant differences between RA2 and RA3 in the ANOVA study.

\section{Acknowledgements}

The authors gratefully acknowledge the support of the Architectural Construction and Control Department's laboratory of the Technical University School of Architecture (Madrid Polytechnic University) and the Chemistry and Polymers Department's laboratory of the University School of Technical Industrial Engineering (Madrid Polytechnic University).

The authors are also grateful to the BASF Construction Chemicals España S.L. for their technical support.

\section{Standards used in the experimental work}

Spanish Ministry of Public Works. Instrucción de Hormigón Estructural EHE-08 (Spanish Structural Concrete Code). BOE 2008; 203:258-66.

UNE 83115:1989 EX. Friability coefficient (In Spanish).

UNE-EN 12370:1999. Natural stone test methods. Determination of resistance to salt crystallization.

UNE-EN 12371:2001. Natural stone test methods. Determination of frost resistance.

UNE-EN-933-1:2012. Tests for geometrical properties of aggregates - Part 1: Determination of particle size distribution Sieving method.

UNE-EN-933-2:1995. Test for geometrical properties of aggregates - Part 2: Determination of particle size distribution. Test sieves, nominal size of apertures.

UNE-EN 998-1:2010. Specification for mortar for masonry Part 1: Rendering and plastering mortar.

UNE-EN 1015-2:1998. Methods of test for mortar for masonry Part 2: Bulk sampling of mortars and preparation of test mortars.

UNE-EN 1015-6:1998. Methods of test for mortar for masonry Part 6: Determination of bulk density of fresh mortar.

UNE-EN 1015-9:1999. Methods of test for mortar for masonry Part 9: Determination of workable life and correction time of fresh mortar.
UNE-EN 1015-10:1999. Methods of test for mortar for masonry - Part 10: Determination of dry bulk density of hardened mortar.

UNE-EN 1015-11:1999. Methods of test for mortar for masonry - Part 11: Determination of flexural and compressive strength of hardened mortar.

UNE-EN 1015-12:2000. Methods of test for mortar for masonry - Part 12: Determination of adhesive strength of hardened rendering and plastering mortars on substrates.

UNE-EN 1015-18:2002. Methods of test for mortar for masonry - Part 18: Determination of water absorption coefficient due to capillary action of hardened mortar.

UNE-EN-1097-3:1998. Tests for mechanical and physical properties of aggregates - Part 3: Determination of loose bulk density and voids.

UNE-EN-1097-6:2001. Tests for mechanical and physical properties of aggregates - Part 6: Determination of particle density and water absorption.

UNE-EN 13139:2002. Aggregates for mortar.

\section{References}

Angulo, S.C., Ulsen, C., John, V.M., Kahn, H., Cincotto, M.A., 2009. Chemical-mineralogical characterization of C\&D waste recycled aggregates from Sao Paulo, Brazil. Waste Manag. 29, 721-730.

Bravo, M., De Brito, J., Pontes, J., Evangelista, L., 2015. Mechanical performance of concrete made with aggregates from construction and demolition waste recycling plants. J. Clean. Prod. 99, 59-74.

Corinaldesi, V., 2012. Environmentally-friendly bedding mortars for repair of historical buildings. Constr. Build. Mater. 35, 778-784.

Corinaldesi, V., Moriconi, G., 2009. Behaviour of cementitious mortars containing different kinds of recycled aggregate. Constr. Build. Mater. 23, 289-294.

Etxeberria, M., Vázquez, E., Marí, A., Barra, M., 2007. Influence of amount of recycled coarse aggregates and production process on properties of recycled aggregate concrete. Cem. Concr. Res. 37, 735-742.

Eurostat, Environment and Energy, 2010. Generation and Treatment of Waste. Available in: http://ec.europa.eu/eurostat/.

Fernández, E., Jiménez, J.R., Ayuso, J., Fernández, J.M., de Brito, J., 2015. Maximum feasible use of recycled sand from construction and demolition waste for ecomortar production - part-I: ceramic masonry waste. J. Clean. Prod. 87, $692-706$.

Jiménez, J.R., Ayuso, I., López, M., Fernández, J.M., De Brito, J., 2013. Use of fine recycled aggregates from a ceramic waste in masonry mortar manufacturing. Constr. Build. Mater. 40, 679-690.

Khatig, J.M., 2005. Properties of concrete incorporating fine recycled aggregates. Cem. Concr. Res. 35, 763-769.

Lamond, J.F., Campbell, R.L., Campbell, J.A., Giraldi, A., Halczak, W., Hale, H.C., 2002. Removal and reuse of hardened concrete: reported by $\mathrm{ACl}$ committee $555 . \mathrm{ACl}$ Mater. J. 99, 300-325.

Martínez, I., Etxeberria, M., Pavón, E., Díaz, N., 2013. A comparative analysis of the properties of recycled and natural aggregate in masonry mortars. Constr. Build. Mater 49, 384-392.

Mesbah, H.A., Buyle-Bodin, F., 1999. Efficiency of polypropylene and metallic fibres on control of shrinkage and cracking of recycled aggregate mortars. Constr. Build. Mater. 13, 439-447.

Provecto Gear, 2012. Gú́a española de áridos reciclados procedentes de Residuos de Construcción y Demolición (RCD). Fueyo editores, ISBN 978-84-939391-2-0.

Shi-Cong, K., Chi-Sun, P., 2009. Properties of concrete prepared with crushed fine stone, furnace bottom ash and fine recycled aggregate as fine aggregates. Constr. Build. Mater. 23, 2877-2886.

Silva, J., de Brito, J., Veiga, R., 2009. Incorporation of fine ceramics in mortars. Constr. Build. Mater. 23, 556-564

Silva, J., De Brito, J., Veiga, R., 2010. Recycled red-clay ceramic construction and demolition waste for mortars productions. J. Mater. Civ. Eng. 22, 236-244.

Tam, V.W.Y., Wang, K., Tam, C.M., 2008. Assessing relationship among properties of demolished concrete, recycled aggregate and recycled aggregate concrete using regression analysis. J. Hazard. Mater. 152, 703-714.

Vegas, I., Ibáñez, J.A., San José, J.T., Urzelai, A., 2008. Construction demolition wastes, Waelz slag and MSWI bottom ash: a comparative technical analysis as material for road construction. Waste Manag. 28, 565-574.

Vegas, I., Azkarate, I., Juarrero, A., Frias, M., 2009. Design and performance of masonry mortars made with recycled concrete aggregates. Mater. Constr. 95 (295), $5-18$.

Villoria, P., del Río, M., Porras, C., de San Antonio, A., 2011. European legislation and implementation measures in the management of construction and demolition waste. Open Constr. Build. Technol. J. 5 (Suppl. 2-M6), 156-161. 